OPEN ACCESS

Edited by:

Tian Zhang,

Technical University of Denmark, Denmark

Reviewed by: Liang Shi,

Wright State University, USA Tom Clarke,

University of East Anglia, UK

*Correspondence:

Ricardo O. Louro,

Inorganic Biochemistry and NMR Laboratory, Instituto de Tecnologia Química e Biológica António Xavier,

Universidade Nova de Lisboa, Avenida da República da República (EAN), 2780-157 Oeiras, Portugal louro@itqb.unl.pt

Specialty section:

This article was submitted to Microbiotechnology, Ecotoxicology and Bioremediation, a section of the journal Frontiers in Microbiology

Received: 29 April 2015 Accepted: 17 June 2015

Published: 29 June 2015

Citation:

Alves MN, Neto SE, Alves AS, Fonseca BM, Carrêlo A, Pacheco I,

Paquete CM, Soares CM and Louro RO (2015) Characterization of the periplasmic redox network that sustains the versatile anaerobic metabolism of Shewanella oneidensis

Front. Microbiol. 6:665. doi: 10.3389/fmicb.2015.00665

\section{Characterization of the periplasmic redox network that sustains the versatile anaerobic metabolism of Shewanella oneidensis MR-1}

\author{
Mónica N. Alves, Sónia E. Neto, Alexandra S. Alves, Bruno M. Fonseca, Afonso Carrêlo, \\ Isabel Pacheco, Catarina M. Paquete, Cláudio M. Soares and Ricardo O. Louro* \\ Inorganic Biochemistry and NMR Laboratory, Instituto de Tecnologia Química e Biológica António Xavier, Universidade Nova \\ de Lisboa, Oeiras, Portugal
}

The versatile anaerobic metabolism of the Gram-negative bacterium Shewanella oneidensis MR-1 (SOMR-1) relies on a multitude of redox proteins found in its periplasm. Most are multiheme cytochromes that carry electrons to terminal reductases of insoluble electron acceptors located at the cell surface, or bona fide terminal reductases of soluble electron acceptors. In this study, the interaction network of several multiheme cytochromes was explored by a combination of NMR spectroscopy, activity assays followed by UV-visible spectroscopy and comparison of surface electrostatic potentials. From these data the small tetraheme cytochrome (STC) emerges as the main periplasmic redox shuttle in SOMR-1. It accepts electrons from CymA and distributes them to a number of terminal oxidoreductases involved in the respiration of various compounds. STC is also involved in the electron transfer pathway to reduce nitrite by interaction with the octaheme tetrathionate reductase (OTR), but not with cytochrome $c$ nitrite reductase (ccNiR). In the main pathway leading the metal respiration STC pairs with flavocytochrome $c$ (FccA), the other major periplasmic cytochrome, which provides redundancy in this important pathway. The data reveals that the two proteins compete for the binding site at the surface of MtrA, the decaheme cytochrome inserted on the periplasmic side of the MtrCAB-OmcA outer-membrane complex. However, this is not observed for the MtrA homologues. Indeed, neither STC nor FccA interact with MtrD, the best replacement for MtrA, and only STC is able to interact with the decaheme cytochrome DmsE of the outer-membrane complex DmsEFABGH. Overall, these results shown that STC plays a central role in the anaerobic respiratory metabolism of SOMR1. Nonetheless, the trans-periplasmic electron transfer chain is functionally resilient as a consequence of redundancies that arise from the presence of alternative pathways that bypass/compete with STC.

Keywords: dissociation constant, electron transfer, electrostatics, extracellular respiration, paramagnetic NMR, periplasmic cytochromes, Shewanella oneidensis MR-1

Abbreviations: SOMR-1, Shewanella oneidensis MR-1; MFC, microbial fuel cell; STC, small tetraheme cytochrome; FccA, flavocytochrome $c$; OTR, octaheme tetrathionate reductase; $\mathrm{ccNiR}$, Cytochrome $c$ nitrite reductase. 


\section{Introduction}

Shewanella oneidensis MR-1 is a Gram-negative bacterium that can use a wide range of terminal electron acceptors in the absence of oxygen, including fumarate, nitrite, nitrate, trimethylamine oxide (TMAO), dimethyl sulfoxide (DMSO), sulfur compounds and a variety of metal compounds including radionuclides (Myers and Nealson, 1988; Nealson and Saffarini, 1994; Myers and Myers, 2000; Gralnick and Newman, 2007; Burns and DiChristina, 2009). This metabolic versatility has made SOMR-1 a target of biotechnological research for the development of novel bioremediation processes and generation of electricity in MFC (Lovley, 2006; Logan and Rabaey, 2012). Electron transfer from SOMR-1 to extracellular substrates relies on the conduction of electrons from the cytoplasm to the cell surface via a periplasmic network of redox proteins dominated by $c$-type cytochromes (Heidelberg et al., 2002; Hau and Gralnick, 2007). With the exception of thiosulfate and TMAO reduction, all forms of anaerobic respiration described in SOMR-1 are routed via the tetraheme $c$-type cytochrome CymA, anchored to the inner membrane of the cell (Myers and Myers, 1997; Saffarini et al., 2002). This protein collects electrons from the menaquinone pool in the cytoplasmic membrane and distributes them among periplasmic proteins. These proteins can be either terminal reductases or periplasmic redox shuttles that transfer electrons to outer-membrane reductases (Myers and Myers, 1997; Saffarini et al., 2002; Schwalb et al., 2003). Nevertheless, the detailed organization of the trans-periplasmic redox network remains to be completely elucidated (Hartshorne et al., 2009). In anaerobic conditions, the most abundant periplasmic c-type cytochromes in SOMR-1 are the STC and the FccA (Tsapin et al., 2001). It was recently shown that both STC and FccA can accept electrons from CymA and transfer them to outer-membrane metal reductases, which lead to the identification of two independent redox pathways across the periplasm (Fonseca et al., 2013). Although this finding confirmed the functional redundancy already observed for other multiheme cytochromes (Coursolle and Gralnick, 2010; Richardson et al., 2012), the physiological reason for this is still unknown. One of the most explored and well described anaerobic respiratory pathways in SOMR-1 is $\mathrm{Fe}(\mathrm{III})$ reduction, which involves the outer membrane MtrCABOmcA complex (Myers and Nealson, 1988; Myers and Myers, 1997, 2000; Pitts et al., 2003). However, less is known about the periplasmic electron transfer network that delivers electrons to the homologous complexes, MtrDEF and DmsEFABGH. While the DmsEFABGH complex is responsible for the extracellular respiration of DMSO, the specific physiological function of MtrDEF is still unclear. It appears to play a similar role to MtrCAB-OmcA complex because of their high similarity (Fredrickson et al., 2008; Coursolle and Gralnick, 2010).

Another important respiratory process carried out by SOMR1 is the conversion of nitrogen compounds to ammonia (Myers and Nealson, 1988; Nealson and Saffarini, 1994). This respiratory pathway involves the OTR and the cytochrome $c$ nitrite reductase (ccNiR). OTR is described as an efficient nitrite and hydroxylamine reductase and ccNiR catalyzes the reduction of nitrite (Einsle et al., 2002; Atkinson et al., 2007). It was previously demonstrated that CymA is essential for nitrite reduction (Schwalb et al., 2003), but nothing is known about the routes of electron transfer to OTR and $c c N i R$. In order to determine if STC and FccA mediate the electron transfer from CymA to the outer-membrane complexes MtrDEF and DmsEFABGH, protein interactions studied by Nuclear magnetic resonance (NMR) and UV-visible spectroscopy were performed. NMR spectroscopy together with protein electrostatic surface potential calculations was also used to explore the ability of STC and FccA transfer electrons to OTR and ccNiR (Mowat et al., 2004; Youngblut et al., 2012). These results showed that the functional redundancy between STC and FccA appears to be restricted to the interaction with the MtrCAB-OmcA complex. Furthermore, the data showed that STC plays the major role in connecting CymA with the DmsEFABGH complex and OTR, but is not involved in interactions neither with ccNiR nor with MtrD.

\section{Materials and Methods}

\section{Cloning and Expression of the Genes of Interest}

The vectors containing $d m s E$ and $m t r D$ genes were kindly provided by Dr. Liang Shi from the Pacific Northwest National Laboratory (Richland, WA, U.S.A.). A stop codon was inserted at the $3^{\prime}$ end of each gene, allowing the removal of the V5 epitope and the $6 \mathrm{xHis}$-tag sequence at the $\mathrm{C}$-terminus of the proteins. The lack of these sequences eliminated concerns about proper folding of the protein in the presence of the 6xHis-tag at the C-terminus. The cloning vector pHSG298 (Takara Bio), containing the ccnir gene with the wild-type $\mathrm{N}$-terminal signal peptide replaced by the signal peptide from the SOMR-1 protein STC, was gently provided by Dr. Sean J. Elliott from Boston University. The otr gene was amplified from genomic DNA of SOMR-1 and cloned into the pBAD202/D-TOPO vector following the instructions from the supplier (pBAD202 directional TOPO Expression Invitrogen KIT) and according to the work of Shi et al. (2005). The primers used are reported in Table 1.

\section{Bacterial Strains and Growth Conditions}

Shewanella oneidensis JG207 strain (knockout strain of the $f c c A$ gene), kindly provided by Prof. Dr. Johannes Gescher from Karlsruher Institut für Technologie (Karlsruher, Germany), was transformed with the vector containing the otr gene. The vectors containing the $d m s E$ and $m t r D$ genes were separately transformed in SOMR-1. S. oneidensis cells were grown at $30^{\circ} \mathrm{C}$ in Terrific Broth (TB) containing $50 \mu \mathrm{g} / \mathrm{ml}$ kanamycin in $5 \mathrm{l}$ Erlenmeyer flasks containing 21 of medium and 1:100 inoculum volume, at $130 \mathrm{rev} . / \mathrm{min}$. Protein expression was induced by addition of L-arabinose: $1 \mathrm{mM}$ (for the strains over-expressing DmsE and OTR) and $2 \mathrm{mM}$ (for the strain over-expressing MtrD) after 6-8 h of growth. After induction, cells continued to grow for $16 \mathrm{~h}$, until harvesting. Bacterial cells were harvested by centrifugation at $11,325 \mathrm{~g}$ for $10 \mathrm{~min}$, at $4^{\circ} \mathrm{C}$. In this study the strain SOMR-1 was used to express ccNiR employing the growth conditions previously reported in the literature (Judd et al., 2012). The vectors, strains and growth conditions to express MtrA, STC, 
TABLE 1 | Primers used in this study.

\begin{tabular}{|c|c|}
\hline Primer & Sequence $\left(5^{\prime}-3^{\prime}\right)$ \\
\hline DmsE_Stop_Forw & GCGGCAGCAATाTGCCCGTTGAGGCGAGCTCAAGCTTGAAGGTAAGCC \\
\hline DmsE_Stop_Rev & GGCTTACCTTCAAGCTTGAGCTCGCCTCAACGGGCAAAATTGCTGCCGC \\
\hline MtrD_Stop_Forw & AAGTTGCTGCAGAGATAAGGCGAGCTCAAGCTTGA \\
\hline MtrD_Stop_Rev & TCAAGCTTGAGCTCGCCTTATCTCTGCAGCAACTT \\
\hline OTR_Stop_Forw & CACCTAAGAAGGAGATATACATCCCATGAA \\
\hline OTR_Stop_Rev & TTATTGCTTATGTITAGGGCCTTGTTTGTT \\
\hline
\end{tabular}

FccA, and CymA were as previously described (Fonseca et al., 2009, 2013).

\section{Protein Purification}

The cell pellets were resuspended in $20 \mathrm{mM}$ Tris- $\mathrm{HCl}(\mathrm{pH}$ 7.6) containing protease inhibitor cocktail (Roche) and DNase I (Sigma). The disruption of the cells was achieved by a passage through a French Press at 1000 psi. Membranes and cell debris were removed by centrifugation at $219,000 \mathrm{~g}$ for $1 \mathrm{~h}$, at $4^{\circ} \mathrm{C}$, and the supernatant containing the soluble protein fraction was dialyzed overnight against 41 of $20 \mathrm{mM}$ Tris- $\mathrm{HCl}$ ( $\mathrm{pH} 7.6$ ). These fractions were concentrated in ultrafiltration cells, using a $10 \mathrm{kDa}$ cut-off membrane. The fractions containing each of the target proteins were loaded onto a diethylaminoethyl (DEAE) column (GE Healthcare) pre-equilibrated with $20 \mathrm{mM}$ Tris-HCl ( $\mathrm{pH}$ 7.6). A gradient from 0 to $1 \mathrm{M} \mathrm{NaCl}$ was applied. The fractions containing MtrD were eluted at $150 \mathrm{mM}$ $\mathrm{NaCl}$, while DmsE and OTR were eluted at $200 \mathrm{mM} \mathrm{NaCl}$. The fractions containing DmsE and MtrD were concentrated and loaded onto a HTP (hydroxyapatite) column (Bio-Rad Laboratories) pre-equilibrated with $10 \mathrm{mM}$ potassium phosphate buffer ( $\mathrm{pH} 7.6$ ) and gradient from $10 \mathrm{mM}$ to $1 \mathrm{M}$. DmsE and MtrD were eluted at 100 and $150 \mathrm{mM}$ of potassium phosphate buffer ( $\mathrm{pH}$ 7.6), respectively. The final purification step used a Superdex 75 column (GE Healthcare) pre-equilibrated with $20 \mathrm{mM}$ potassium phosphate buffer ( $\mathrm{pH}$ 7.6) and $100 \mathrm{mM} \mathrm{NaCl}$. The fraction resulting from the DEAE column containing OTR was concentrated and loaded onto a Q-Sepharose column (GE Healthcare) previously equilibrated with $20 \mathrm{mM}$ Tris- $\mathrm{HCl}(\mathrm{pH}$ 7.6). A salt gradient from 0 to $1 \mathrm{M} \mathrm{NaCl}$ was applied and this protein was eluted at $150 \mathrm{mM} \mathrm{NaCl}$. The fraction containing OTR was concentrated and loaded onto a HTP column preequilibrated with $10 \mathrm{mM}$ potassium phosphate buffer ( $\mathrm{pH}$ 7.6). A gradient from $10 \mathrm{mM}$ to $1 \mathrm{M}$ of potassium phosphate buffer ( $\mathrm{pH}$ 7.6) was applied, and pure OTR was eluted at $100 \mathrm{mM}$. The purification of STC, FccA, CymA, and ccNiR cytochromes was performed as described in the literature (Judd et al., 2012; Fonseca et al., 2013). The recombinant TEV protease was removed from the fraction containing $c c N i R$ using a Superdex 75 column pre-equilibrated with $20 \mathrm{mM}$ potassium phosphate buffer $(\mathrm{pH}$ 7.6) with $150 \mathrm{mM} \mathrm{KCl}$. All the chromatographic fractions were analyzed by SDS/PAGE stained for heme proteins (Francis and Becker, 1984) and by UV-visible spectroscopy to select those containing the target proteins. Proteins were considered pure when having an absorbance ratio Soret Peak/A280nm higher than 3.5, and when showing a single band in Coomassie staining
SDS/PAGE gels. The identity of DmsE, MtrD, and OTR was confirmed by mass spectrometry and $\mathrm{N}$-terminal sequencing.

\section{NMR Sample Preparation and Titrations}

Stock samples of DmsE, MtrD, OTR, ccNiR, STC, and FccA in $20 \mathrm{mM}$ potassium phosphate $(\mathrm{pH} 7.6)$ with an ionic strength of $100 \mathrm{mM}$ (adjusted by addition of potassium chloride) were lyophilized and dissolved in ${ }^{2} \mathrm{H}_{2} \mathrm{O}$ (99.9 atom\%, Spectra Stable Isotopes). NMR spectra obtained before and after lyophilization were identical, demonstrating that the proteins were not affected by this procedure. The protein concentration was determined by UV-visible spectroscopy using $\varepsilon_{410 \mathrm{~nm}}$ of $125,000 \mathrm{M}^{-1} \mathrm{~cm}^{-1}$ per heme for the oxidized state of the protein (Massey, 1959; Hartshorne et al., 2007). Samples containing 50 or $100 \mu \mathrm{M}$ of STC and FccA were titrated against increasing concentrations of DmsE, MtrD, OTR, and ccNiR. The competition titration was performed with a sample of $\operatorname{MtrA}(50 \mu \mathrm{M})$ incubated with sufficient amount of FccA to have at least $90 \%$ of MtrA bound to FccA. Subsequently, increasing amounts of STC were added to the NMR tube, in order to detect any perturbation in STC signals. ${ }^{1} \mathrm{H}-1 \mathrm{D}-\mathrm{NMR}$ spectra were recorded after each addition. The chemical shifts of the signals corresponding to the methyl substituents of the hemes of STC and FccA were measured in each spectrum. These signals have been previously assigned to specific hemes in the structure, allowing the identification of the docking sites with its redox partners (Fonseca et al., 2009; Pessanha et al., 2009).

Nuclear magnetic resonance experiments were performed at $25^{\circ} \mathrm{C}$ on a Bruker Avance II spectrometer operating at $500 \mathrm{MHz}$ equipped with a TXI probe. The proton spectra were calibrated using the water signal as an internal reference (Banci et al., 1995).

\section{Data Analysis and Binding Affinities}

Chemical shift perturbations equal to or larger than $0.025 \mathrm{ppm}$ were considered significant (Diaz-Moreno et al., 2005b). The chemical shift perturbations $\left(\Delta \delta_{\text {bind }}\right)$ of the NMR signals from a cytochrome resulting from the complex formation with another cytochrome were plotted against the molar ratio (R) of $[\mathrm{CytB}] /[\mathrm{Cyt} A]$. The data were fitted using least squares minimization to a 1:1 binding model using equations (1) and (2) (Worrall et al., 2003):

$$
\begin{aligned}
& \Delta \delta_{\text {bind }}=\frac{1}{2} \Delta \delta_{\text {bind }}^{\infty}\left(A-\sqrt{\left(A^{2}-4 R\right)}\right) \\
& A=1+R+\frac{K_{d}\left(\left[C y t_{A}\right]_{0} R+\left[C y t_{B}\right]_{0}\right)}{\left[C y t_{A}\right]_{0}\left[C y t_{B}\right]_{0}}
\end{aligned}
$$


where $\Delta \delta_{b i n d}^{\infty}$ is the maximal chemical shift perturbation of the NMR signals resulting from the complex formation between Cyt $_{A}$ and $\mathrm{Cyt}_{\mathrm{B}}, \mathrm{K}_{\mathrm{d}}$ is the dissociation constant, $\left[\mathrm{Cyt}_{\mathrm{A}}\right]_{0}$ is the initial concentration of $\mathrm{Cyt}_{\mathrm{A}}$ and $\left[\mathrm{Cyt}_{\mathrm{B}}\right]_{0}$ is the stock concentration of $\mathrm{Cyt}_{\mathrm{B}}$. When several methyl signals belonging to an individual heme were visible, the data obtained for all methyls were used to define the dissociation constant. Experimental uncertainty was estimated from the spectral resolution of the NMR data acquired.

\section{Spectroscopic Assay of Interprotein Electron Transfer}

Electron transfer involving FccA from SOMR-1 was measured spectrophotometrically inside an anaerobic chamber using an UV-visible spectrophotometer (Shimadzu model UV-1800) to collect spectra in the range of $300-800 \mathrm{~nm}$ as previously described. Briefly, an approximate final concentration of $1 \mu \mathrm{M}$ of each target protein was prepared in a $1 \mathrm{ml}$ cuvette. Dilutions were made from stock solutions of DmsE, MtrD, OTR, ccNiR, and FccA in degassed $20 \mathrm{mM}$ potassium phosphate buffer $(\mathrm{pH}$ 7.6) with $100 \mathrm{mM} \mathrm{KCl}$. Each protein was reduced by addition of small amounts of a concentrated solution of sodium dithionite. The absorbance was monitored at $314 \mathrm{~nm}$ to avoid excess of reducing agent. Fumarate was added to the reduced protein solutions to a final concentration of $\sim 1 \mathrm{mM}$. Only when no change was observed in absorbance at $552 \mathrm{~nm}$, the reaction would be initiated by the addition of $1 \mathrm{nM} \mathrm{FccA}$. The spectral changes were monitored over time. Experiments were performed with constant stirring and the temperature was kept at $25^{\circ} \mathrm{C}$ using an external thermostatic bath.

\section{Protein Electrostatic Surface Potential Calculations}

The structures of ccNiR (PDB code 3UBR; Youngblut et al., 2012) and the OTR (PDB code 1SP3; Mowat et al., 2004), were used to calculate the electrostatic potential at the surface of both proteins. Both proteins were set in their fully oxidized states, which were the experimental conditions used to study their interactions. The GROMOS 43A1 force field (Scott et al., 1999) was used to set the partial charges of the proteins and co-factors. The MEAD package (Bashford and Karplus, 1990), which solves the PoissonBoltzmann equation for a system, was used to calculate the electrostatic potentials. The ionic strength used was $0 \mathrm{mM}$ and the internal and external dielectric constants were set at 2 and 80 , respectively. The electrostatic potential was mapped at the surface of the proteins using PyMOL (DeLano, 2003).

\section{Results}

\section{NMR Titrations and Binding Affinities}

For electron transfer to occur at physiologically relevant rates between two cytochromes, the heme groups of donor and acceptor must be in close proximity (Zhang et al., 2008; Gray and Winkler, 2010). Therefore, when multiheme cytochromes bind in a configuration that is relevant for interprotein electron transfer, NMR spectroscopy can be used to detect this binding through observation of changes in the chemical shifts of signals belonging to the hemes near to the binding sites (Fonseca et al., 2013). This technique is thus highly suited to study interactions between the redox proteins found in the periplasmic space of SOMR-1, revealing the detailed organization of its transperiplasmic redox network. Figure 1 illustrates spectral changes for the $18^{1}$ methyl signal (IUPAC-IUB nomenclature) from heme IV $\left(18^{1} \mathrm{CH}_{3}{ }^{\mathrm{IV}}\right)$ of STC in the presence of increasing amounts of OTR.

Chemical shift perturbations of the STC and FccA signals, resulting from binding to putative redox partners, were plotted against the molar ratio of redox partner:STC and redox partner:FccA (Figure 2). All the periplasmic pairs of proteins tested and $K_{d}$ values of proteins that showed interactions are reported in Table 2. In some cases, such as the signals of the $2^{1}$ methyl of heme III or the $18^{1}$ methyl of hemes II and IV of STC during interaction with DmsE, the chemical shift perturbation of their signals is smaller than $0.025 \mathrm{ppm}$. These are therefore of insufficient magnitude for a confident estimation of binding parameters as indicated in the Section "Materials and Methods" and were not used in the calculations. The $\mathrm{K}_{\mathrm{d}}$ values calculated are typical of weakly transient interactions as reported for other cytochromes (Diaz-Moreno et al., 2005a; Perkins et al., 2010; Bashir et al., 2011; Meschi et al., 2011; Fonseca et al., 2013).

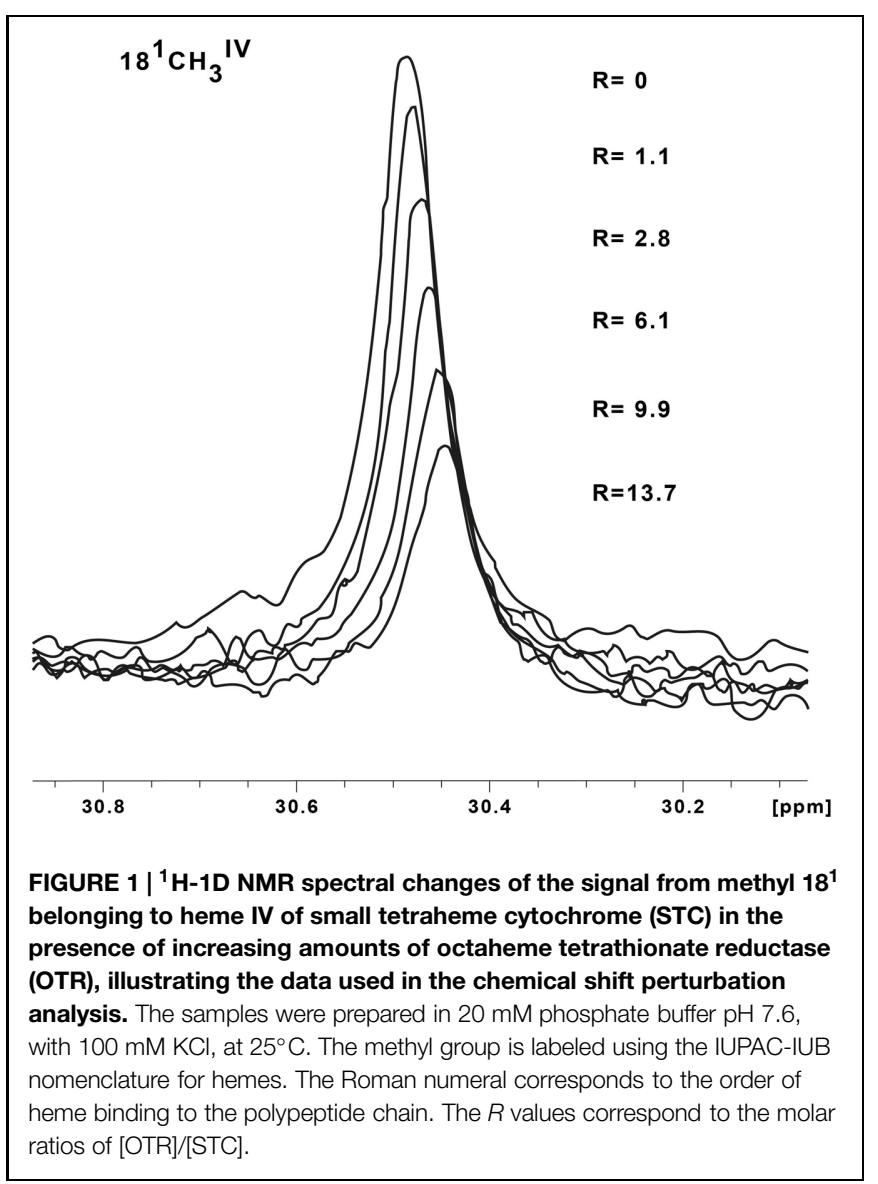



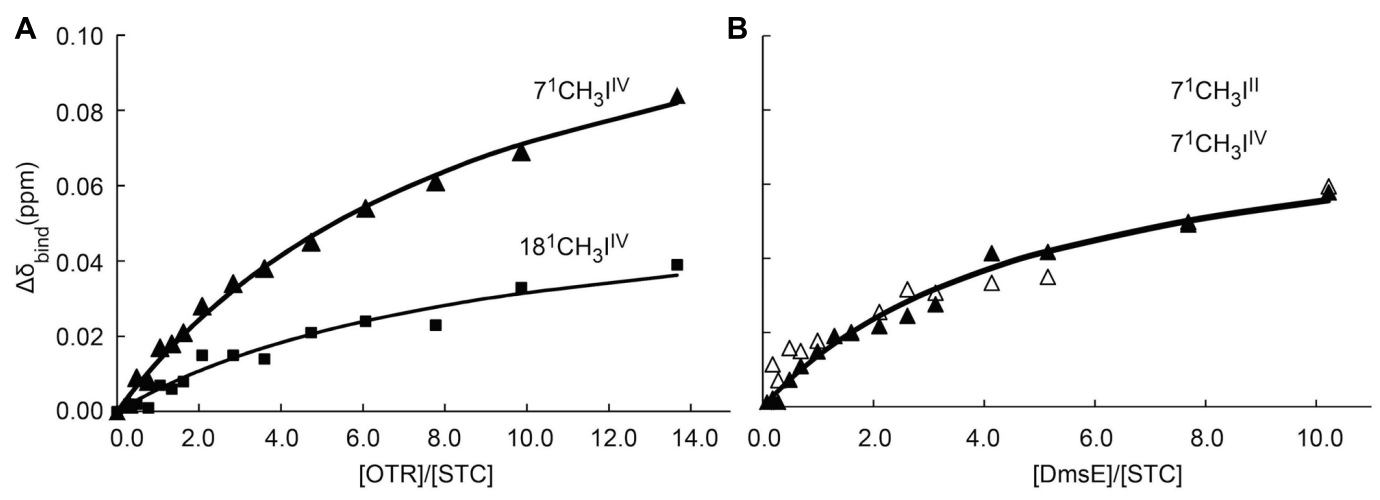

FIGURE 2 | Binding curves of periplasmic cytochromes from SOMR-1 that show interactions monitored by ${ }^{1} \mathrm{H}-1 \mathrm{D}-\mathrm{NMR}$ spectra: OTR and STC (A) and DmsE and STC (B). The chemical shift perturbations of the heme methyl signals are plotted as a function of the molar ratio of the interacting proteins. Solid triangles and solid squares represent the $7^{1}$ methyl and $18^{1}$ methyl of heme IV of STC, respectively; open triangles represent the $7^{1}$ methyl of heme II of STC. The solid lines represent the best global fit to the 1:1 binding model [equation (1)].
TABLE 2 | Pairwise interactions tested for cytochromes found in the periplasm of SOMR-1.

\begin{tabular}{lll}
\hline Cytochrome Complex & $\mathbf{K}_{\mathbf{d}}(\boldsymbol{\mu} \mathbf{M})$ & Docking Site \\
\hline FccA and MtrA & $35(14)$ & Heme II \\
FccA and DmsE & - & \\
FCCA and MtrD & - & \\
FccA and OTR & - & \\
FcCA and CcNiR & - & Heme IV \\
STC and MtrA & $572(5)$ & Hemes II,III, and IV \\
STC and DmsE & $783(227)$ & Heme IV \\
STC and MtrD & - & \\
STC and OTR & $1600(400)$ & \\
STC and ccNiR & - &
\end{tabular}

The "-" symbol indicates no interaction detected. Values in parenthesis are standard errors obtained from the diagonal of the covariance matrix arising from the fitting of the binding model to the experimental data.

Previous studies showed that both STC and FccA interact with the decaheme cytochrome MtrA and that the affinity between
FccA and MtrA is much stronger than the affinity between STC and MtrA (Fonseca et al., 2013). Given that the three-dimensional structure of MtrA is not yet available, a competition binding assay monitored by ${ }^{1} \mathrm{H}-1 \mathrm{D}-\mathrm{NMR}$ was performed to study the docking place of STC and FccA with MtrA. In conditions where more than $90 \%$ of MtrA is bound to FccA, the chemical shift of the STC signals are not perturbed when the molar ratio of MtrA:STC is changed (Figure 3). This result shows that the presence of FccA bound to MtrA prevents the interaction between MtrA and STC, suggesting that the binding of STC and FccA at the surface of MtrA occurs in the same place or in close proximity.

The inverse competition binding assay with MtrA saturated with bound STC in the presence of increasing amounts of FccA added to the sample is not experimentally feasible. To reach more than $90 \%$ saturation of a sample with $50 \mu \mathrm{M}$ of $\mathrm{MtrA}$ with STC would require concentrations of STC above $5 \mathrm{mM}$. Likewise, a similar experiment exploring the interactions of STC and FccA with CymA, another key protein for which a structure has not been reported in the literature, is not also
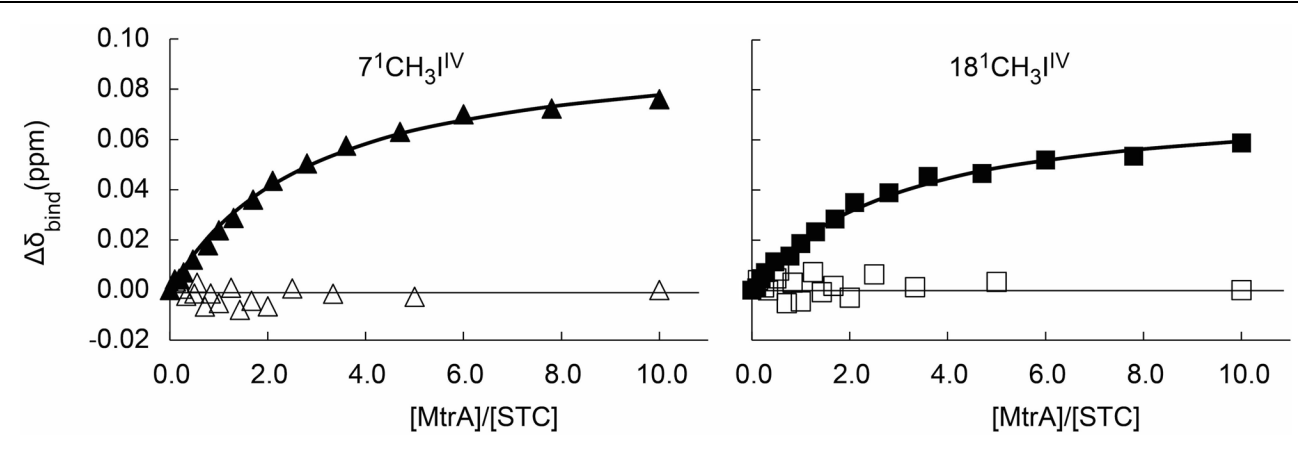

FIGURE 3 | Competition binding curves between STC and FccA with MtrA monitored by ${ }^{\mathbf{1}} \mathbf{H}$-1D NMR spectra. The chemical shift perturbations of the heme methyl signals are plotted as a function of the molar ratio of the interacting proteins. Filled symbols represent the experiment performed in the absence of FccA (Fonseca et al., 2013), whereas open symbols represent the experiment in the presence of $360 \mu \mathrm{M}$ of FccA to ensure that more than $90 \%$ of MtrA is bound to FccA. The solid lines represent the best global fit to the 1:1 binding model [equation (1)] as reported by Fonseca et al. (2013). 


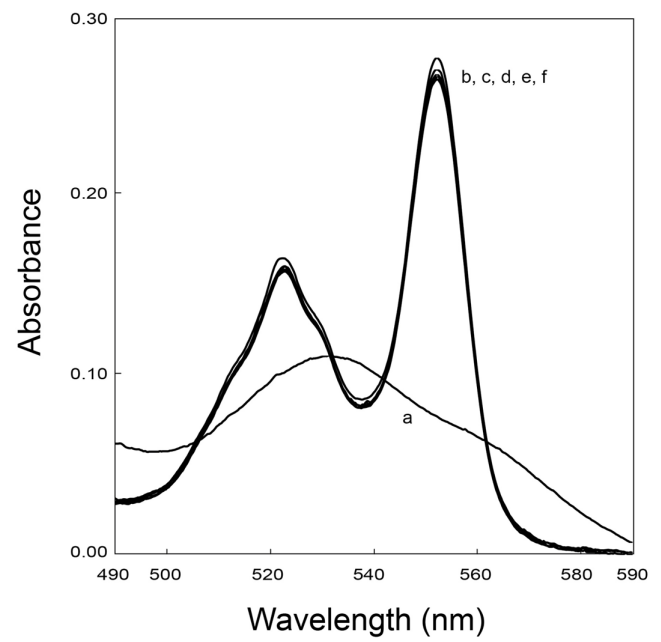

FIGURE 4 | UV-visible spectroscopy of reduced periplasmic cytochromes in the presence of excess fumarate and catalytic amounts of FccA illustrating the absence of electron transfer between OTR with FccA. UV-visible spectrum of the cytochrome as purified (a), after reduction with sodium dithionite (b) and subsequent addition of fumarate (c). After addition of FccA to the mixture, spectra were acquired at 0 min (d), $2.5 \mathrm{~min}(\mathrm{e})$, and $5 \mathrm{~min}(\mathrm{f})$. The samples were prepared in $20 \mathrm{mM}$ phosphate buffer $\mathrm{pH} 7.6$, with $100 \mathrm{mM} \mathrm{KCl}$, at $25^{\circ} \mathrm{C}$. require concentrations of STC and FccA of 2.2 and $3.5 \mathrm{mM}$, respectively.

\section{Spectroscopic Assay of Interprotein Electron Transfer}

UV-visible experiments were performed to confirm the interaction data obtained from NMR experiments involving FccA. The fumarate reductase activity of FccA was used to measure the re-oxidation of possible partner cytochromes. These experiments showed that FccA cannot re-oxidize MtrD, DmsE, OTR, and ccNiR (Figure 4), which is in agreement with the data obtained from NMR titrations.

\section{Electrostatic Calculations}

The electrostatic potential at the surfaces of the enzymes ccNiR and OTR were calculated using the same procedure as previously used for STC and FccA (Fonseca et al., 2013). OTR presents an overall negative surface, with the exception of two regions, one near heme II (the catalytic heme) and the other one near heme VIII. In the case of $\mathrm{ccNiR}$, the surface potential does not show a clear cut trend as in the case of OTR, with the exception of the region near heme I, which is the catalytic heme. The region around this heme is strongly negative (Figure 5).

\section{Discussion}

The electron transfer pathways of the SOMR-1 to reduce $\mathrm{Fe}(\mathrm{III})$, DMSO, fumarate and nitrite are established by a variety of multiheme $c$-type cytochromes located at the inner membrane, periplasm and outer membrane. Biochemical studies experimentally feasible. The large dissociation constants reported for the interaction between STC and CymA or FccA and CymA (Fonseca et al., 2013) mean that achieving more than $90 \%$ saturation of $50 \mu \mathrm{M}$ CymA with any of the partners would
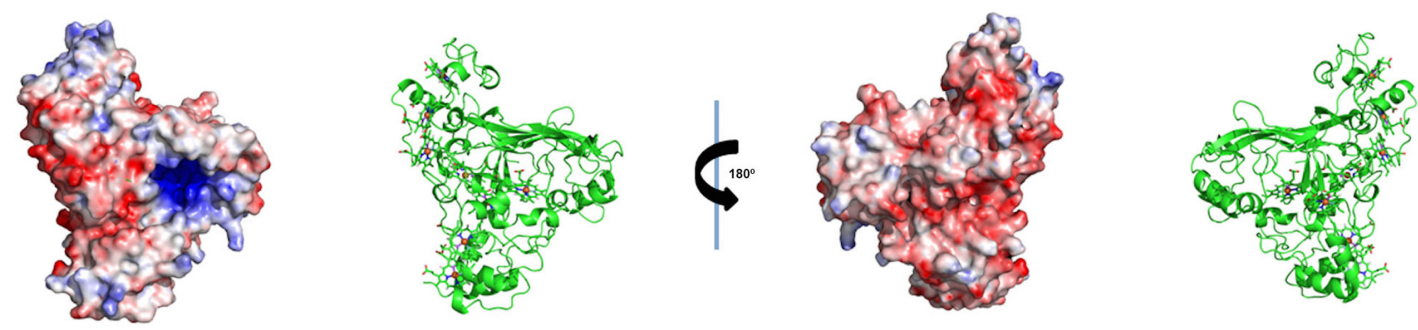

B
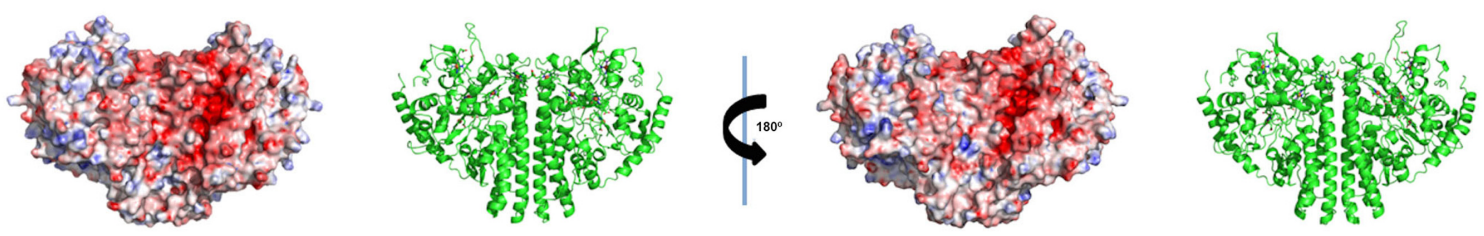

$-10 \mathrm{kT} / \mathrm{e}$

$10 \mathrm{kT} / \mathrm{e}$

FIGURE 5 | Electrostatic potential mapping on the protein's surface of (A) OTR (PDB code 1S3P) and (B) ccNiR (PDB code3UBR) from SOMR-1. Electrostatic potentials were calculated considering a fully oxidized state for these cytochromes. The Roman numerals correspond to the order of heme binding motifs in the polypeptide chain. 
showed that all of these routes have the common feature of being initiated by the oxidation of the quinone pool at the inner-membrane by the tetraheme $c$-type cytochrome, CymA (Schwalb et al., 2003; Marritt et al., 2012). The detailed understanding of the organization of the trans-periplasmic redox network has been compounded by two factors: spectroscopic signatures of $c$-type cytochromes are often overlapping or identical (Firer-Sherwood et al., 2011), and they form low-affinity complexes with fast dissociation rates (Crowley and Ubbink, 2003; Rudolph, 2007; Abresch et al., 2009). Nevertheless, recent studies have demonstrated that NMR spectroscopy is an effective technique to identify transient interactions between redox partners by monitoring the perturbation of the chemical shifts of heme signals (Fonseca et al., 2013). This method does not disturb the protein conformation because it is a soluble assay. Furthermore, it has the unique advantage of allowing the determination of docking regions between redox partners when resonance assignments of the interacting proteins are available.

A previous study revealed that STC and FccA can independently mediate electron transfer between CymA and MtrA leading to extracellular electron transfer (Fonseca et al., 2013). Since the three-dimensional structure of MtrA was only characterized at low resolution using SAXS (Firer-Sherwood et al., 2011), the docking with its redox partners STC and FccA cannot be modeled at this point. Notwithstanding, in this work the interaction of STC and FccA with MtrA was further characterized by a competition binding assay between STC and FccA. It revealed that these two proteins bind MtrA in the same or at least closely related locations, given that saturation of MtrA with FccA prevents the binding of STC.

This study also reveals that STC interacts transiently with DmsE and that the signals of hemes II, III, and IV are perturbed. Clearly, the interaction between STC and DmsE is different from that between STC and MtrA, which affects only signals of the heme IV of STC. Given the bracket shape of the structure of STC, if one considers the hemes ordered sequentially from top to bottom it can be envisaged that interaction with DmsE occurs via the lower external face of the bracket (Supplementary Figure S1).

The genome of SOMR-1 contains three homologues of the MtrCAB-OmcA complex, the MtrDEF complex, the DmsEFABGH complex and the complex coded by the genes SO_4357-62. Studies involving MtrA knockout strains showed that two of these complexes constitute alternative routes of

TABLE 3 | Sequence identity matrix for the periplasmic decaheme cytochromes from SOMR-1.

\begin{tabular}{llccc}
\hline & MtrA & MtrD & DmsE & SO4360 \\
\hline MtrA & 100 & 72 & 69 & 54 \\
MtrD & ++ & 100 & 60 & 49 \\
DmsE & + & & 100 & 51 \\
SO4360 & - & & & 100 \\
\hline
\end{tabular}

Sequences of the four decaheme cytochromes were retrieved from Pubmed-NCBI database and aligned using the Clustal 2.1 Multiple Sequence Alignment website. Values are presented in percentage. Below the diagonal is an indication of the relative ability to functionally replace MtrA according to Coursolle and Gralnick (2010). electron flow to $\mathrm{Fe}(\mathrm{III})$ respiration (Coursolle and Gralnick, 2010). MtrA can be functionally replaced in ferric citrate reduction in the order MtrD > DmsE (Coursolle and Gralnick, 2012). Despite the high homology of SO4360 with MtrA, this decaheme cytochrome cannot functionally replace MtrA and requires its own porin SO4359 to function in metal reduction (Schicklberger et al., 2013). This hierarchy in the capacity for functional replacement of MtrA matches the sequence homology among these decaheme cytochromes (Table 3) but does not match the observed interactions with the major trans-periplasmic redox shuttles. MtrA interacts with STC and FccA that compete for the same binding site on the surface of MtrA. DmsE interacts with STC but not FccA, and MtrD does not interact with STC or FccA. Altogether, these data give strong indications that the dominant factor in the capacity of other periplasmic decaheme cytochromes to functionally replace MtrA is the matching with the MtrB porin to establish contact with the outer-membrane MtrC cytochrome, since neither STC nor FccA interact with MtrD.

Studies recently published by Sturm et al. (2015) showed that single mutants of STC and FccA have only minor phenotypic changes in their ability to reduce DMSO. However, the double mutant strain is unable to grow using this electron acceptor (Sturm et al., 2015). Those results suggest that both STC and FccA have a key role in the respiration of DMSO in SOMR-1 and the data reported in this work indicates that FccA does not interact directly with DmsE.

In this study, interactions involving two major terminal reductases involved in pathways for dissimilatory nitrate ammonification of SOMR-1, ccNiR, and OTR, were also explored (Berks et al., 1995; Simon, 2002; Einsle and Kroneck, 2004). While the pentaheme ccNiR catalyzes the reduction of nitrite $\left(\mathrm{NO}_{2}{ }^{-}\right)$ to ammonium $\left(\mathrm{NH}_{4}{ }^{+}\right)$, the octaheme OTR can reduce nitrite $\left(\mathrm{NO}_{2}{ }^{-}\right)$and hydroxylamine $\left(\mathrm{NH}_{2} \mathrm{OH}\right)$, as well as the sulfur compound tetrathionate $\left(\mathrm{S}_{4} \mathrm{O}_{6}{ }^{2-}\right)$ (Atkinson et al., 2007). The results showed that heme IV of STC is perturbed upon interaction with OTR. The region around heme IV of STC displays the strongest negative surface, making it a good candidate to interact with OTR that displays positively charged potentials in various regions of its surface (Figure 5). By contrast, no interaction was observed between $c \mathrm{NiR}$ and STC or FccA. The surface of $c \mathrm{NiR}$ is predominantly weakly negative with a strongly negative region near the catalytic center, therefore discouraging interactions with the negatively charged STC or heme domain of FccA. This result is also consistent with a previous study showing that both wildtype SOMR-1 and the $\Delta s t c \Delta f c c A$ mutant strain reduce nitrite at similar rates (Sturm et al., 2015).

Interestingly, all protein-protein interactions reported between STC and its putative physiological partners involve heme IV (Fonseca et al., 2013). Given that to perform its function of shuttling electrons between redox partners STC needs to charge and discharge, clearly this protein does not operate as a molecular wire. It functions more like an electronic cul-de-sac that forces electrons to enter and leave the cytochrome by the same heme. This enables Shewanella to transfer electrons in a controlled and efficient manner (maximum of four electrons can be transferred by STC) to specific proteins in the periplasmic 


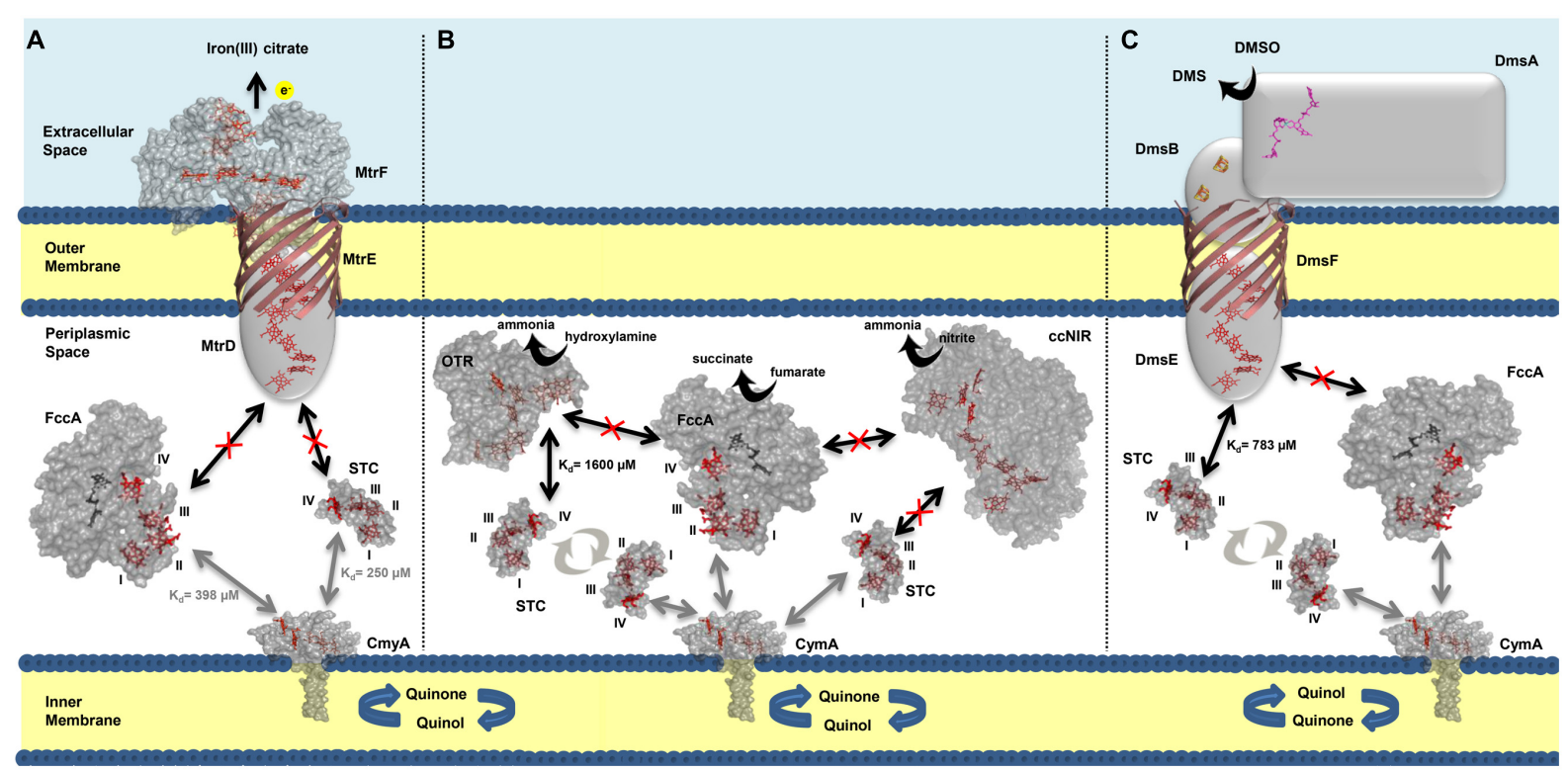

FIGURE 6 | Interactions between the most abundant periplasmic cytochromes (STC and FccA), and outer membrane complex MtrDEF (A), periplasmic nitrite reductases OTR and $\operatorname{ccNiR}(B)$ and outer membrane complex DmsEFABGH (C). The arrows in bold indicate the interactions that occur between the cytochromes and point to the possible docking site. Black arrows indicate data from this work and gray arrows indicate data previously reported (Fonseca et al., 2013). The dissociation constants $(\mathrm{Kd})$ corresponding to each interaction are indicated next to their respective arrow. Interactions that were not detected experimentally are represented by a crossed-out arrow. The Roman numerals correspond to the order of heme attachment to the polypeptide chain. Cytochrome representations were made with PyMOL using the structures of STC (PDB code 1M1Q), FCcA (PDB code 1D4D), OTR (PDB code 1S3P), and ccNiR (PDB code 3UBR). For CymA the model was made with SWISS-MODEL (Arnold et al., 2006; Kiefer et al., 2009) using as template the structure of $\mathrm{NrfH}$ (PDB code 2J7A). space, rather than transfer randomly to any protein that may interact with STC. This minimizes the risk of diverting electrons to side redox pathways and production of radical species.

\section{Conclusion}

We have elucidated the organization of the multi-branched periplasmic respiratory network of SOMR-1. NMR studies revealed that STC not only contributes to extracellular respiration of metals via interaction with MtrCAB-OmcA, but also to the reduction of nitrogen compounds and DMSO by interacting with OTR and DmsE, respectively (Figure 6). These results demonstrate that STC is a promiscuous periplasmic electron shuttle with a variety of redox partners. Notwithstanding, STC is clearly selective in the mode of interaction with its multiple partners that always appears to involve the participation of heme IV. Interestingly, in contrast to STC, no interaction was observed between FccA with MtrD, DmsE, OTR, and ccNiR. These results contrast with the functional redundancy that FccA provides for STC revealed by delayed or no growth with ferric citrate, DMSO or nitrite as electron acceptors (Sturm et al., 2015) in double deletion mutant studies. Further studies will reveal whether the differences arise from different metabolic regulation in the mutant strains or if FccA interacts indirectly with partners in those metabolic pathways.

\section{Acknowledgments}

We thank Dr. Liang Shi from the Pacific Northwest National Laboratory (Richland, WA, USA) for providing the cloning vectors (pBAD202/D-TOPO) containing the $d m s E$ and $m t r D$ genes. We thank Dr. Sean J. Elliott from Boston University for providing with the cloning vector pHSG298 containing the ccnir gene, and Prof. Dr. Johannes Gescher from Karlsruhe Institut für Technologie for providing the S. oneidensis JG207 strain. This work was supported by Fundação para a Ciência e a Tecnologia (FCT)-Portugal [Grants REEQ/336/BIO/2005, PTDC/BIA-PRO/117523/2010, SFRH/BPD/96952/2013 (to CP), and SFRH/BPD/93164/2013 (to BF)]. The NMR experiments were performed at the National NMR Facility supported by FCT (RECI/BBB-BQB/0230/2012). Mass spectrometry data were obtained by the Mass Spectrometry Laboratory, Analytical Services Unit, Instituto de Tecnologia Química e Biológica. N-terminal sequencing was obtained by the Analytical Laboratory, Analytical Services Unit, Instituto de Tecnologia Química e Biológica, Universidade Nova de Lisboa.

\section{Supplementary Material}

The Supplementary Material for this article can be found online at: http://journal.frontiersin.org/article/10.3389/fmicb. 2015.00665 


\section{References}

Abresch, E. C., Gong, X. M., Paddock, M. L., and Okamura, M. Y. (2009). Electron transfer from cytochrome $c(2)$ to the reaction center: a transition state model for ionic strength effects due to neutral mutations. Biochemistry 48, 11390-11398. doi: 10.1021/bi901332t

Arnold, K., Bordoli, L., Kopp, J., and Schwede, T. (2006). The SWISSMODEL workspace: a web-based environment for protein structure homology modelling. Bioinformatics 22, 195-201. doi: 10.1093/bioinformatics/bti770

Atkinson, S. J., Mowat, C. G., Reid, G. A., and Chapman, S. K. (2007). An octaheme c-type cytochrome from Shewanella oneidensis can reduce nitrite and hydroxylamine. FEBS Lett. 581, 3805-3808. doi: 10.1016/j.febslet.2007. 07.005

Banci, L., Pierattelli, R., and Turner, D. L. (1995). Determination of haem electronic structure in cytochrome b5 and metcyanomyoglobin. Eur. J. Biochem. 232, 522-527. doi: 10.1111/j.1432-1033.1995.522zz.x

Bashford, D., and Karplus, M. (1990). pKa's of ionizable groups in proteins: atomic detail from a continuum electrostatic model. Biochemistry 29, 10219-10225. doi: 10.1021/bi00496a010

Bashir, Q., Scanu, S., and Ubbink, M. (2011). Dynamics in electron transfer protein complexes. FEBS J. 278, 1391-1400. doi: 10.1111/j.1742-4658.2011.08062.x

Berks, B. C., Ferguson, S. J., Moir, J. W., and Richardson, D. J. (1995). Enzymes and associated electron transport systems that catalyse the respiratory reduction of nitrogen oxides and oxyanions. Biochim. Biophys. Acta 1232, 97-173. doi: 10.1016/0005-2728(95)00092-5

Burns, J. L., and DiChristina, T. J. (2009). Anaerobic respiration of elemental sulfur and thiosulfate by Shewanella oneidensis MR-1 requires psrA, a homolog of the phsA gene of Salmonella enterica serovar typhimurium LT2. Appl. Environ. Microbiol. 75, 5209-5217. doi: 10.1128/AEM.00888-09

Coursolle, D., and Gralnick, J. A. (2010). Modularity of the Mtr respiratory pathway of Shewanella oneidensis strain MR-1. Mol. Microbiol. 77, 995-1008. doi: 10.1111/j.1365-2958.2010.07266.x

Coursolle, D., and Gralnick, J. A. (2012). Reconstruction of extracellular respiratory pathways for Iron(III) reduction in Shewanella oneidensis strain MR-1. Front. Microbiol. 3:56. doi: 10.3389/fmicb.2012.00056

Crowley, P. B., and Ubbink, M. (2003). Close encounters of the transient kind: protein interactions in the photosynthetic redox chain investigated by NMR spectroscopy. Acc. Chem. Res. 36, 723-730. doi: 10.1021/ar0200955

DeLano, W. L. (2003). The PyMOL Molecular Graphics System. San Carlos, CA: DeLano Scientific LLC.

Diaz-Moreno, I., Diaz-Quintana, A., Molina-Heredia, F. P., Nieto, P. M., Hansson, O., De la Rosa, M. A., et al. (2005a). NMR analysis of the transient complex between membrane photosystem I and soluble cytochrome c6. J. Biol. Chem. 280, 7925-7931. doi: 10.1074/jbc.M412422200

Diaz-Moreno, I., Diaz-Quintana, A., Ubbink, M., and De la Rosa, M. A. (2005b). An NMR-based docking model for the physiological transient complex between cytochrome f and cytochrome c6. FEBS Lett. 579, 2891-2896. doi: 10.1016/j.febslet.2005.04.031

Einsle, O., and Kroneck, P. M. (2004). Structural basis of denitrification. Biol. Chem. 385, 875-883. doi: 10.1515/BC.2004.115

Einsle, O., Messerschmidt, A., Huber, R., Kroneck, P. M., and Neese, F. (2002). Mechanism of the six-electron reduction of nitrite to ammonia by cytochrome c nitrite reductase. J. Am. Chem. Soc. 124, 11737-11745. doi: 10.1021/ja02 06487

Firer-Sherwood, M. A., Bewley, K. D., Mock, J. Y., and Elliott, S. J. (2011) Tools for resolving complexity in the electron transfer networks of multiheme cytochromes c. Metallomics 3, 344-348. doi: 10.1039/c0mt00097c

Fonseca, B. M., Paquete, C. M., Neto, S. E., Pacheco, I., Soares, C. M., and Louro, R. O. (2013). Mind the gap: cytochrome interactions reveal electron pathways across the periplasm of Shewanella oneidensis MR-1. Biochem. J. 449, 101-108. doi: 10.1042/BJ20121467

Fonseca, B. M., Saraiva, I. H., Paquete, C. M., Soares, C. M., Pacheco, I., Salgueiro, C. A., et al. (2009). The tetraheme cytochrome from Shewanella oneidensis MR1 shows thermodynamic bias for functional specificity of the hemes. J. Biol. Inorg. Chem. 14, 375-385. doi: 10.1007/s00775-008-0455-7

Francis, R. T. Jr., and Becker, R. R. (1984). Specific indication of hemoproteins in polyacrylamide gels using a double-staining process. Anal. Biochem. 136, 509-514. doi: 10.1016/0003-2697(84)90253-7
Fredrickson, J. K., Romine, M. F., Beliaev, A. S., Auchtung, J. M., Driscoll, M. E., Gardner, T. S., et al. (2008). Towards environmental systems biology of Shewanella. Nat. Rev. Microbiol. 6, 592-603. doi: 10.1038/nrmicro1947

Gralnick, J. A., and Newman, D. K. (2007). Extracellular respiration. Mol. Microbiol. 65, 1-11. doi: 10.1111/j.1365-2958.2007.05778.x

Gray, H. B., and Winkler, J. R. (2010). Electron flow through metalloproteins. Biochim. Biophys. Acta 1797, 1563-1572. doi: 10.1016/j.bbabio.2010.05.001

Hartshorne, R. S., Jepson, B. N., Clarke, T. A., Field, S. J., Fredrickson, J., Zachara, J., et al. (2007). Characterization of Shewanella oneidensis MtrC: a cell-surface decaheme cytochrome involved in respiratory electron transport to extracellular electron acceptors. J. Biol. Inorg. Chem. 12, 1083-1094. doi: 10.1007/s00775-007-0278-y

Hartshorne, R. S., Reardon, C. L., Ross, D., Nuester, J., Clarke, T. A., and Gates, A. J., (2009). Characterization of an electron conduit between bacteria and the extracellular environment. Proc. Natl. Acad. Sci. U.S.A. 106, 22169-22174. doi: 10.1073/pnas.0900086106

Hau, H. H., and Gralnick, J. A. (2007). Ecology and biotechnology of the genus Shewanella. Annu. Rev. Microbiol. 61, 237-258. doi: 10.1146/annurev.micro.61.080706.093257

Heidelberg, J. F., Paulsen, I. T., Nelson, K. E., Gaidos, E. J., Nelson, W. C., Read, T. D., et al. (2002). Genome sequence of the dissimilatory metal ionreducing bacterium Shewanella oneidensis. Nat. Biotechnol. 20, 1118-1123. doi: $10.1038 /$ nbt749

Judd, E. T., Youngblut, M., Pacheco, A. A., and Elliott, S. J. (2012). Direct electrochemistry of Shewanella oneidensis cytochrome $\mathrm{c}$ nitrite reductase: evidence of interactions across the dimeric interface. Biochemistry 51, 1017510185. doi: $10.1021 /$ bi3011708

Kiefer, F., Arnold, K., Kunzli, M., Bordoli, L., and Schwede, T. (2009). The SWISS-MODEL repository and associated resources. Nucleic Acids Res. 37, D387-D392. doi: 10.1093/nar/gkn750

Logan, B. E., and Rabaey, K. (2012). Conversion of wastes into bioelectricity and chemicals by using microbial electrochemical technologies. Science 337, 686-690. doi: 10.1126/science.1217412

Lovley, D. R. (2006). Bug juice: harvesting electricity with microorganisms. Nat. Rev. Microbiol. 4, 497-508. doi: 10.1038/nrmicrol 442

Marritt, S. J., Lowe, T. G., Bye, J., McMillan, D. G., Shi, L., Fredrickson, J., et al. (2012). A functional description of CymA, an electron-transfer hub supporting anaerobic respiratory flexibility in Shewanella. Biochem. J. 444, 465-474. doi: 10.1042/BJ20120197

Massey, V. (1959). The microestimation of succinate and the extinction coefficient of cytochrome c. Biochim. Biophys. Acta 34, 255-256. doi: 10.1016/00063002(59)90259-8

Meschi, F., Wiertz, F., Klauss, L., Blok, A., Ludwig, B., Merli, A., et al. (2011). Efficient electron transfer in a protein network lacking specific interactions. J. Am. Chem. Soc. 133, 16861-16867. doi: 10.1021/ja205043f

Mowat, C. G., Rothery, E., Miles, C. S., McIver, L., Doherty, M. K., Drewette, K., et al. (2004). Octaheme tetrathionate reductase is a respiratory enzyme with novel heme ligation. Nat. Struct. Mol. Biol. 11, 1023-1024. doi: $10.1038 / \mathrm{nsmb} 827$

Myers, C. R., and Myers, J. M. (1997). Isolation and characterization of a transposon mutant of Shewanella putrefaciens MR-1 deficient in fumarate reductase. Lett. Appl. Microbiol. 25, 162-168. doi: 10.1046/j.1472765X.1997.00196.x

Myers, C. R., and Nealson, K. H. (1988). Bacterial manganese reduction and growth with manganese oxide as the sole electron acceptor. Science 240, 1319-1321. doi: $10.1126 /$ science. 240.4857 .1319

Myers, J. M., and Myers, C. R. (2000). Role of the tetraheme cytochrome CymA in anaerobic electron transport in cells of Shewanella putrefaciens MR-1 with normal levels of menaquinone. J. Bacteriol. 182, 67-75. doi: 10.1128/JB.182.1.67-75.2000

Nealson, K. H., and Saffarini, D. (1994). Iron and manganese in anaerobic respiration: environmental significance, physiology, and regulation. Annu. Rev. Microbiol. 48, 311-343. doi: 10.1146/annurev.mi.48.100194.001523

Perkins, J. R., Diboun, I., Dessailly, B. H., Lees, J. G., and Orengo, C. (2010). Transient protein-protein interactions: structural, functional, and network properties. Structure 18, 1233-1243. doi: 10.1016/j.str.2010.08.007

Pessanha, M., Rothery, E. L., Miles, C. S., Reid, G. A., Chapman, S. K., Louro, R. O., et al. (2009). Tuning of functional heme reduction potentials in 
Shewanella fumarate reductases. Biochim. Biophys. Acta 1787, 113-120. doi: 10.1016/j.bbabio.2008.11.007

Pitts, K. E., Dobbin, P. S., Reyes-Ramirez, F., Thomson, A. J., Richardson, D. J., and Seward, H. E. (2003). Characterization of the Shewanella oneidensis MR1 decaheme cytochrome MtrA: expression in Escherichia coli confers the ability to reduce soluble Fe(III) chelates. J. Biol. Chem. 278, 27758-27765. doi: 10.1074/jbc.M302582200

Richardson, D. J., Butt, J. N., Fredrickson, J. K., Zachara, J. M., Shi, L., Edwards, M. J., et al. (2012). The "porin-cytochrome" model for microbe-tomineral electron transfer. Mol. Microbiol. 85, 201-212. doi: 10.1111/j.13652958.2012.08088.x

Rudolph, J. (2007). Inhibiting transient protein-protein interactions: lessons from the Cdc25 protein tyrosine phosphatases. Nat. Rev. Cancer 7, 202-211. doi: $10.1038 / \mathrm{nrc} 2087$

Saffarini, D. A., Blumerman, S. L., and Mansoorabadi, K. J. (2002). Role of menaquinones in $\mathrm{Fe}(\mathrm{III})$ reduction by membrane fractions of Shewanella putrefaciens. J. Bacteriol. 184, 846-848. doi: 10.1128/JB.184.3.846-848.2002

Schicklberger, M., Sturm, G., and Gescher, J. (2013). Genomic plasticity enables a secondary electron transport pathway in Shewanella oneidensis. Appl. Environ. Microbiol. 79, 1150-1159. doi: 10.1128/AEM.03556-12

Schwalb, C., Chapman, S. K., and Reid, G. A. (2003). The tetraheme cytochrome CymA is required for anaerobic respiration with dimethyl sulfoxide and nitrite in Shewanella oneidensis. Biochemistry 42, 9491-9497. doi: 10.1021/bi034456f

Scott, W., Hünenberger, P., Tironi, I., Mark, A., Billeter, S., Fennen, J., et al. (1999). The GROMOS biomolecular simulation program package. J. Phys. Chem. A 103, 3596-3607. doi: 10.1021/jp984217f

Shi, L., Lin, J. T., Markillie, L. M., Squier, T. C., and Hooker, B. S. (2005). Overexpression of multi-heme C-type cytochromes. Biotechniques 38, 297-299. doi: 10.2144/05382PT01

Simon, J. (2002). Enzymology and bioenergetics of respiratory nitrite ammonification. FEMS Microbiol. Rev. 26, 285-309. doi: 10.1111/j.1574-6976. 2002.tb00616.x
Sturm, G., Richter, K., Doetsch, A., Heide, H., Louro, R. O., and Gescher, J. (2015). A dynamic periplasmic electron transfer network enables respiratory flexibility beyond a thermodynamic regulatory regime. ISME J. doi: 10.1038/ismej.2014.264 [Epub ahead of print].

Tsapin, A. I., Vandenberghe, I., Nealson, K. H., Scott, J. H., Meyer, T. E., Cusanovich, M. A., et al. (2001). Identification of a small tetraheme cytochrome $\mathrm{c}$ and a flavocytochrome $\mathrm{c}$ as two of the principal soluble cytochromes $\mathrm{c}$ in Shewanella oneidensis strain MR1. Appl. Environ. Microbiol. 67, 3236-3244. doi: 10.1128/AEM.67.7.3236-3244.2001

Worrall, J. A., Reinle, W., Bernhardt, R., and Ubbink, M. (2003). Transient protein interactions studied by NMR spectroscopy: the case of cytochrome C and adrenodoxin. Biochemistry 42, 7068-7076. doi: 10.1021/bi0342968

Youngblut, M., Judd, E. T., Srajer, V., Sayyed, B., Goelzer, T., Elliott, S. J., et al. (2012). Laue crystal structure of Shewanella oneidensis cytochrome c nitrite reductase from a high-yield expression system. J. Biol. Inorg. Chem. 17, 647-662. doi: 10.1007/s00775-012-0885-0

Zhang, H., Chobot, S. E., Osyczka, A., Wraight, C. A., Dutton, P. L., and Moser, C. C. (2008). Quinone and non-quinone redox couples in Complex III. J. Bioenerg. Biomembr. 40, 493-499. doi: 10.1007/s10863-008-9174-6

Conflict of Interest Statement: The authors declare that the research was conducted in the absence of any commercial or financial relationships that could be construed as a potential conflict of interest.

Copyright (C) 2015 Alves, Neto, Alves, Fonseca, Carrêlo, Pacheco, Paquete, Soares and Louro. This is an open-access article distributed under the terms of the Creative Commons Attribution License (CC BY). The use, distribution or reproduction in other forums is permitted, provided the original author(s) or licensor are credited and that the original publication in this journal is cited, in accordance with accepted academic practice. No use, distribution or reproduction is permitted which does not comply with these terms. 